\title{
Diagnosis and management of feline hyperthyroidism: current perspectives
}

This article was published in the following Dove Press journal:

Veterinary Medicine: Research and Reports

20 August 2014

Number of times this article has been viewed

\section{Heather H Vaske \\ Thomas Schermerhorn \\ Laura Armbrust \\ Gregory F Grauer}

Department of Clinical Sciences, Kansas State University, Manhattan, KS, USA
Correspondence: Gregory Grauer Kansas State University, Veterinary Health Center, 1800 Denison Ave,

Manhattan, KS 66506, USA

Tel +l 7855325690

Fax + I 7855324900

Email ggrauer@vet.k-state.edu

\begin{abstract}
Previous and ongoing research has provided insights to the pathophysiology and diagnosis of hyperthyroidism as well as new treatment modalities. This paper reviews the etiology, clinical presentation, and clinicopathologic changes associated with hyperthyroidism, and provides a thorough explanation of confirmatory testing and treatment options.
\end{abstract}

Keywords: feline hyperthyroidism, diagnosis, management

\section{Introduction}

The clinical condition of feline hyperthyroidism occurs due to excessive production and secretion of the thyroid hormones, thyroxine $\left(\mathrm{T}_{4}\right)$ and triiodothyronine $\left(\mathrm{T}_{3}\right)$. It was first described in humans in 1913 and in cats in $1979 .{ }^{1}$ In cats, hyperthyroidism is almost always a primary autonomous condition of one or both thyroid glands, with most cats $(70 \%)$ having benign adenomatous disease of both glands, ${ }^{2}$ and a minority $(<5 \%)$ having malignant thyroid carcinoma. ${ }^{3,4}$

\section{Etiology}

The etiology of feline hyperthyroidism remains incompletely understood. Due to the increasing prevalence of hyperthyroidism since the syndrome was first identified in cats, the possible contributions of immunologic, nutritional, environmental, and genetic factors have been extensively evaluated. In human beings, hyperthyroidism is typically associated with autoimmune (Graves') disease, and a similar etiology has been investigated in cats. Although some hyperthyroid cats have been found to have autoantibodies mimicking thyroid-stimulating hormone (TSH) that may contribute to the development of hyperthyroidism, ${ }^{5}$ other investigators have not been able to verify this finding. ${ }^{6,7}$ Other studies have suggested an increased incidence of hyperthyroidism in cats fed mostly canned food, or specifically canned foods with fish or liver and giblet flavors. ${ }^{8-11}$ Environmental factors that have been implicated include soy isoflavones, phthalates, resorcinol, polyphenols, and polychlorinated biphenyls, some of which are considered goitrogens and others that can be found in the environment or commercial cat foods. ${ }^{12,13}$ Additionally, cats that are kept primarily indoors, and those that have regular exposure to flea sprays, fertilizers, pesticides, or insecticides, have been found to have an increased prevalence of hyperthyroidism, while Siamese, Himalayan, and purebred cats have been reported to have a decreased risk for hyperthyroidism. ${ }^{8,11,12}$ A direct cause and effect between the above factors and the development of hyperthyroidism remains difficult to prove. 


\section{Clinical presentation}

Cats affected by hyperthyroidism have a mean age of $12-13$ years, with less than $5 \%$ being younger than 10 years of age. ${ }^{14}$ The diagnosis of feline hyperthyroidism involves consideration of clinical signs, physical examination findings, as well as clinicopathologic changes and specific confirmatory testing. Because thyroid hormones have multiple functions throughout the body, almost every organ system is affected by elevated thyroid hormone concentrations. Cats with clinical evidence of thyrotoxicosis typically have a history of weight loss in the face of a normal or increased appetite, increased activity/restlessness, polyuria/polydipsia, an unkempt coat, and gastrointestinal signs, such as vomiting and diarrhea., ${ }^{2,414-16}$ However the severity of these signs has decreased in the past 20 years because the syndrome is recognized earlier in the course of disease, presumably due to increased awareness. ${ }^{2,14-16}$ In addition, approximately $10 \%$ of affected cats exhibit socalled "apathetic hyperthyroidism", which is characterized by decreased appetite and lethargy. ${ }^{2,15}$ More than $90 \%$ of hyperthyroid cats have a palpable thyroid nodule at the time of diagnosis. An elevation in thyroid hormone concentration also causes alterations in cardiovascular hemodynamics, affecting heart rate, heart rhythm, and cardiac output. ${ }^{16-18}$ In hyperthyroid cats, this can be appreciated clinically by the presence of tachycardia, increased intensity of the heart beat, and arrhythmias, as well as a systolic heart murmur (usually grade I-III/VI), which occurs in approximately $50 \%$ of hyperthyroid cats. ${ }^{2,14,15}$ Although these may be common findings on physical examination, congestive heart failure occurs infrequently., ${ }^{214}$ Finally, mild to moderate hypertension was originally thought to be a common finding in hyperthyroid cats, which would resolve with return to a euthyroid state. Current reports indicate that approximately $10 \%$ of cats have hypertension at the time of diagnosis of hyperthyroidism, ${ }^{19}$ and this is associated with a reduced survival time in hyperthyroid cats. ${ }^{20} \mathrm{~A}$ further $20 \%$ of cats develop hypertension following treatment and return to a euthyroid state, which may be associated with the unmasking of renal dysfunction. ${ }^{16,19,21}$

Hematologic and biochemical abnormalities are common with hyperthyroidism. Approximately $40 \%-50 \%$ of cats with hyperthyroidism show slight elevations of packed cell volume, and approximately $20 \%$ develop a macrocytosis. ${ }^{2,14}$ Erythrocyte changes are thought to result from an increased production of erythropoietin secondary to the increase in oxygen consumption that occurs in hyperthyroidism, as well as a direct effect on the bone marrow of thyroid hormonemediated $\beta$-adrenergic stimulation to increase production and release of red blood cells. ${ }^{22}$ Common leukogram changes include neutrophilia, lymphopenia, eosinopenia, and monocytosis. ${ }^{14,15}$ The most common biochemical changes observed in hyperthyroid cats are increased aminotransferase (ALT) and alkaline phosphatase (ALP) levels. In fact, more than $90 \%$ of hyperthyroid cats have an elevation in either ALT or ALP. ${ }^{2,414,15}$ Although elevations in ALT and/or ALP are typically mild, severe elevations can be observed. There are few data regarding the mechanism for liver enzyme elevation in cats with hyperthyroidism; however, in hyperthyroid rats, a direct toxic effect of $\mathrm{T}_{3}$ resulting in lipid peroxidation, protein oxidation, and glutathione depletion of hepatic mitochondria with subsequent apoptosis has been observed. ${ }^{23,24}$ Limited feline studies have shown that both liver and bone ALP isoenzymes contribute to serum ALP elevation in hyperthyroid cats. ${ }^{25-27}$ Although previous recommendations included evaluating hyperthyroid cats with ALP or ALT activity $>500 \mathrm{IU} / \mathrm{L}$ for concurrent disease, , $^{2,14,15}$ further experience has revealed that the changes seen in the liver secondary to hyperthyroidism usually do not affect liver function testing, such as paired serum bile acids, so such testing may not be warranted. ${ }^{28}$ In addition, histologic evaluation of the liver in cats with hyperthyroidism reveals nonspecific and mild changes, ${ }^{4}$ and liver enzyme changes associated with hyperthyroidism usually return to within the reference interval with successful management of the disease. ${ }^{29}$

Urinalysis results in hyperthyroid cats are generally nonspecific; however, many hyperthyroid cats have mild proteinuria. Although the mechanism of proteinuria in hyperthyroid cats is incompletely understood, successful treatment of hyperthyroidism leads to a rapid decrease in urinary protein excretion as assessed by the urine protein to creatinine ratio and urine albumin to creatinine ratio. ${ }^{30-32}$ It has also been reported that up to $12 \%-22 \%$ of hyperthyroid cats present with urinary tract infections. ${ }^{33,34}$ When signalment, history, clinical signs, physical examination findings, and initial blood screenings are compatible with feline hyperthyroidism, additional confirmatory testing is recommended.

\section{Specific thyroid function tests Total $\mathrm{T}_{4}$ concentration}

Although $\mathrm{T}_{3}$ is the biologically active form of thyroid hormone, $\mathrm{T}_{4}$ is the primary hormone secreted from the thyroid gland and found in the circulation, and is later metabolized to $\mathrm{T}_{3}$ in peripheral tissues. ${ }^{35,36}$ Although total $\mathrm{T}_{4}$ concentrations vary considerably throughout the day in cats with hyperthyroidism, more than $90 \%$ of hyperthyroid cats will be confirmed via random serum total $\mathrm{T}_{4}$ testing. ${ }^{4,37,38} \mathrm{In}$ contrast, over $25 \%$ of hyperthyroid cats will have a serum 
total $\mathrm{T}_{3}$ within the reference interval. ${ }^{14,37}$ Thus, circulating serum total $\mathrm{T}_{4}$ is superior to serum total $\mathrm{T}_{3}$ in identifying cats with hyperthyroidism, and is the initial screening test of choice. ${ }^{14,39,40}$ Further, simultaneous measurement of total $\mathrm{T}_{3}$ and total $\mathrm{T}_{4}$ concentrations does not offer a diagnostic advantage over total $\mathrm{T}_{4}$ measurement alone. . $^{14,37,40}$

Serum total $\mathrm{T}_{4}$ concentration measures the protein-bound fraction and free hormone fractions. $\mathrm{T}_{4}$ is highly proteinbound and the free (unbound) fraction makes up less than $1 \%$ of the circulating pool. Radioimmunoassay is the gold standard method for measurement of serum total $\mathrm{T}_{4}$, but methodologic limitations associated with radioimmunoassay have prompted validation of other assay methods, including a homogeneous enzyme immunoassay and chemiluminescent enzyme immunoassay. ${ }^{37,41-44}$ The availability of these methods varies with the laboratory used. In addition, a commercial semiquantitative enzyme-linked immunosorbent assay (ELISA) $\mathrm{T}_{4}$ kit is available for in-house use. The ELISA method has the advantage of providing rapid results to the practitioner, and is accurate when compared with the radioimmunoassay method. ${ }^{43}$ Overall, each of these tests has pros and cons, and the test chosen should be based on the turnaround time needed and test availability.

The total $\mathrm{T}_{4}$ concentration in cats with early or mild hyperthyroidism may fall within the reference interval due to normal fluctuations of thyroid hormones in the circulation. Further, certain drugs and nonthyroid disorders can suppress total thyroid hormone concentrations. The mechanisms for this include altered thyroid hormone metabolism, altered $\mathrm{T}_{4}$ binding within cells or with plasma carrier proteins, and altered transport of $\mathrm{T}_{4}$ into cells. ${ }^{45}$ Of hyperthyroid cats with a total $\mathrm{T}_{4}$ concentration within the reference interval, approximately $20 \%-30 \%$ have concurrent illness and the remaining $70 \%-80 \%$ likely have early disease. ${ }^{37}$ Thus, if a single random serum total $\mathrm{T}_{4}$ value is within the reference interval in a cat with historical, physical examination, and laboratory changes compatible with hyperthyroidism, the total $\mathrm{T}_{4}$ concentration should be determined several weeks later, in addition to ruling out and/or treating any nonthyroid illness. ${ }^{41}$ If nonthyroid illness has been ruled out and a repeat total $\mathrm{T}_{4}$ remains within the reference interval, performing a serum free $\mathrm{T}_{4}$ assay is recommended.

\section{Free $\mathrm{T}_{4}$ concentration}

Serum free $\mathrm{T}_{4}$, the unbound fraction of $\mathrm{T}_{4}$ hormone, represents less than $1 \%$ of total circulating thyroid hormone. Free $\mathrm{T}_{4}$ is the only $\mathrm{T}_{4}$ fraction that can diffuse across cell membranes, and serves as a "prohormone" for $\mathrm{T}_{3}{ }^{36}$ Serum free $\mathrm{T}_{4}$ is a more sensitive test for hyperthyroidism than the serum total $\mathrm{T}_{4}$. More than $95 \%$ of hyperthyroid cats with a total $\mathrm{T}_{4}$ concentration within the reference interval will have an elevated free $\mathrm{T}_{4}$ concentration. ${ }^{37}$ It is generally accepted that cats with a total $\mathrm{T}_{4}$ value in the upper third of the reference interval, an elevated free $\mathrm{T}_{4}$ concentration, and compatible clinical signs, are likely hyperthyroid. ${ }^{4}{ }^{4}$ Because free $\mathrm{T}_{4}$ is the only fraction able to diffuse across cell membranes, it is also the fraction that causes thyrotoxicosis. The free $\mathrm{T}_{4}$ level is also affected by nonthyroid factors. Up to $12 \%$ of euthyroid cats may have an elevated free $\mathrm{T}_{4}$ concentration due to nonthyroid illness, making measurement of free $\mathrm{T}_{4}$ less specific for diagnosis of hyperthyroidism than total $\mathrm{T}_{4}{ }^{37,45,46}$ For this reason, free $T_{4}$ should not be used as the sole diagnostic test for hyperthyroidism. The etiology underlying elevation of circulating free $T_{4}$ in nonthyroid disease is not completely known, but has been speculated to be due to impaired clearance of free $T_{4}$ from the serum. ${ }^{35}$ Finally, hyperthyroid cats with an elevated total $\mathrm{T}_{4}$ concentration will always have a concurrent elevation in free $\mathrm{T}_{4}$ concentration. Therefore, measurement of free $\mathrm{T}_{4}$ is not indicated or necessary if the total $\mathrm{T}_{4}$ is elevated. ${ }^{37}$ If total $\mathrm{T}_{4}$ and free $\mathrm{T}_{4}$ concentrations are found within the reference interval on several separate occasions, but clinical suspicion of hyperthyroidism remains high, additional testing, with, eg, $\mathrm{a}_{3}$ suppression test, thyrotropin-releasing hormone (TRH) stimulation test, TSH response test, or thyroid scintigraphy should be considered.

\section{$T_{3}$ suppression test}

The $T_{3}$ suppression test evaluates the integrity of the physiological feedback loop via which thyroid hormone regulates pituitary gland function. In normal cats, thyroid hormone exerts negative feedback on the hypothalamus and anterior pituitary, and leads to decreased secretion of TRH and TSH, respectively, until inhibition is released by a fall in circulating thyroid hormone concentrations. The $\mathrm{T}_{3}$ suppression test works according to the principle that administration of exogenous $\mathrm{T}_{3}$ to a cat with normal thyroid function suppresses pituitary TSH secretion and leads to a decrease in endogenous $\mathrm{T}_{4}$ secretion. Cats with primary hyperthyroidism, however, secrete thyroid hormones independent of pituitary control. In contrast with normal cats, TSH secretion is chronically suppressed during primary hyperthyroidism, and exogenous $\mathrm{T}_{3}$ administration has little to no effect on endogenous serum $\mathrm{T}_{4}$ concentrations. The $\mathrm{T}_{3}$ suppression test is helpful in distinguishing mildly hyperthyroid cats from euthyroid cats; however, it requires multiple days of treatment for suppression to occur and 
owner compliance is critical. Following collection of baseline serum $\mathrm{T}_{3}$ and $\mathrm{T}_{4}$ samples, owners are instructed to administer $\mathrm{T}_{3}$ hormone (liothyronine; $\mathrm{Cytomel}^{\circledR}$; King Pharmaceuticals Inc., Bristol, TN, USA) $25 \mu \mathrm{g}$ orally three times daily for 2 days, and once on the morning of day 3 , for a total of seven doses. ${ }^{47}$ Two to four hours after the final dose is given, a second $\mathrm{T}_{3}$ and $\mathrm{T}_{4}$ concentration is assessed. The pre-liothyronine and post-liothyronine samples should be submitted to the laboratory at the same time to limit the influence of interassay variation. Cats with hyperthyroidism will have little to no decrease in total $\mathrm{T}_{4}$ concentration after administration of liothyronine, while suppression of total $\mathrm{T}_{4}$ concentration of $50 \%$ or more will occur in euthyroid cats. ${ }^{47}$ Lack of $\mathrm{T}_{4}$ suppression could also be the result of poor compliance with test instructions and may yield falsepositive results. Compliance can be gauged by comparing $\mathrm{T}_{3}$ concentrations before and after the test. If the liothyronine was administered correctly, the final $\mathrm{T}_{3}$ concentration will be elevated above the initial sample. If this does not occur, owner compliance should be questioned, and the test result should be considered invalid.

\section{TRH stimulation test}

A TRH stimulation test also evaluates the integrity of the pituitary-thyroid gland feedback system via administration of TRH. TRH from the hypothalamus stimulates release of TSH from the anterior pituitary gland to increase synthesis and release of thyroid hormones from the thyroid gland. Administration of exogenous $\mathrm{TRH}$ to a cat with normal thyroid function will increase TSH secretion and increase serum total $\mathrm{T}_{4}$ concentrations. To perform a TRH stimulation test, a serum $\mathrm{T}_{4}$ sample is collected before and 4 hours after intravenous administration of $0.1 \mathrm{mg} / \mathrm{kg} \mathrm{TRH} .{ }^{48}$ Cats with even mild hyperthyroidism should have little $(<50 \%)$ or no increase in serum total $\mathrm{T}_{4}$ concentration due to hyperthyroidinduced chronic suppression of endogenous TSH. Clinically healthy cats and cats with nonthyroid disease should have an increase in serum $\mathrm{T}_{4}$ concentrations of $>60 \%{ }^{48}$ This test is considered as reliable as a $\mathrm{T}_{3}$ suppression test; however, the only preparation of TRH approved by the US Food and Drug Administration is no longer available, side effects are common following administration of $\mathrm{TRH},{ }^{48}$ and results can be difficult to determine, especially in cats with concurrent illness, ${ }^{49}$ so, in general, this test is not recommended.

\section{TSH response test}

A TSH response test is typically utilized to aid in the diagnosis of hypothyroidism in dogs, but also has the potential to differentiate euthyroid cats from those with hyperthyroidism. ${ }^{4}$ The protocol involves obtaining a baseline serum total $\mathrm{T}_{4}$ value, followed by administration of intravenous TSH and collection of a second total $\mathrm{T}_{4}$ sample 6-8 hours later. Hyperthyroid cats should have little or no response to exogenous administration of TSH; however, results can be difficult to interpret due to overlap in total $\mathrm{T}_{4}$ response in euthyroid and hyperthyroid cats. ${ }^{29,40,45}$ In addition, the bovine TSH initially utilized for this test is no longer available, and the response to administration of recombinant human TSH has not been evaluated in hyperthyroid cats. Therefore, this test is currently not recommended for the diagnosis of hyperthyroidism, and should only be utilized for diagnosis of canine hypothyroidism. . $29,40,45^{-}$

\section{Random TSH concentration testing}

Measuring a random circulating TSH concentration to detect subclinical hyperthyroidism may be helpful. Cats with subclinical hyperthyroidism should have a low circulating TSH concentration before elevation in total $\mathrm{T}_{4}$ occurs. ${ }^{50}$ When evaluating hyperthyroid cats, normal cats, and cats with chronic kidney disease, it was found that all hyperthyroid cats had TSH values below the quantification value. ${ }^{45}$ However, five of 40 nonhyperthyroid cats also had TSH levels below the quantification value, and the presence of chronic kidney disease did not appear to affect TSH concentrations. ${ }^{45}$ Furthermore, in 104 client-owned cats, TSH concentrations were evaluated with the hypothesis that geriatric euthyroid cats with undetectable TSH concentrations would have an increased risk of developing clinical hyperthyroidism. ${ }^{50}$ Although the cats with undetectable baseline TSH concentrations were significantly more likely to be diagnosed with hyperthyroidism within 14 months, only about half of the cats with undetectable baseline TSH concentrations became hyperthyroid within the 14-month study period. ${ }^{50}$ Ultimately, further studies are needed to determine the utility of measuring a random circulating TSH level in cats.

\section{Thyroid scintigraphy}

If the results of thyroid hormone tests are equivocal but clinical suspicion remains high, thyroid scintigraphy should be considered to confirm hyperthyroidism. In addition to confirming hyperthyroidism, thyroid scintigraphy can also provide information that aids in treatment decisions, and is the best way to detect metastasis of malignant thyroid tumors. Multiple radionuclides have been utilized for imaging the thyroid glands. The use of radioactive iodine $\left({ }^{131} \mathrm{I}\right.$ or $\left.{ }^{123} \mathrm{I}\right)$ has been described; however, radioactive technetium-99m 
(pertechnetate; ${ }^{99 \mathrm{~m}} \mathrm{TcO}_{4}$ ) is the radionuclide most commonly used. ${ }^{99} \mathrm{TcO}_{4}$ is trapped and concentrated within thyroid follicular cells because the molecular configuration of ${ }^{99 \mathrm{~m}} \mathrm{TcO}_{4}$ mimics the size and charge of iodide. ${ }^{4,51}{ }^{99} \mathrm{TcO}_{4}$ is the radionuclide of choice for routine thyroid imaging due to its low cost, short half-life, rapid uptake by the thyroid, low-energy $\gamma$-particle emission, and lack of $\beta$-emission. ${ }^{4,51}$ After intravenous injection of ${ }^{99 \mathrm{~m}} \mathrm{TcO}_{4}$, concentration of the radionuclide within the thyroid tissue occurs over 20-120 minutes and all functioning thyroid tissue can be detected using a gamma camera. ${ }^{2,451-53}$ In normal cats, pertechnetate concentrates in salivary and thyroid tissue to a similar degree, and to a lesser degree in epithelial tissues such as the gastric mucosa. ${ }^{51}$ The normal thyroid glands are elongated ovals of similar size and location bilaterally. Thyroid activity is assessed by comparing the ratio of ${ }^{99 \mathrm{~m}} \mathrm{TcO}_{4}$ uptake by the thyroid gland with uptake by the zygomatic molar salivary gland using a region of interest drawn around the salivary tissue and thyroid tissue (Figure 1). The thyroid to salivary gland uptake ratio is approximately 1:1 in normal cats and more than 1:1 in hyperthyroidism. ${ }^{51,52}$ The increase in thyroid to salivary ratio is directly proportional to thyroid gland function. ${ }^{52}$

As previously discussed, most hyperthyroid cats have bilateral disease, even if not appreciated by cervical

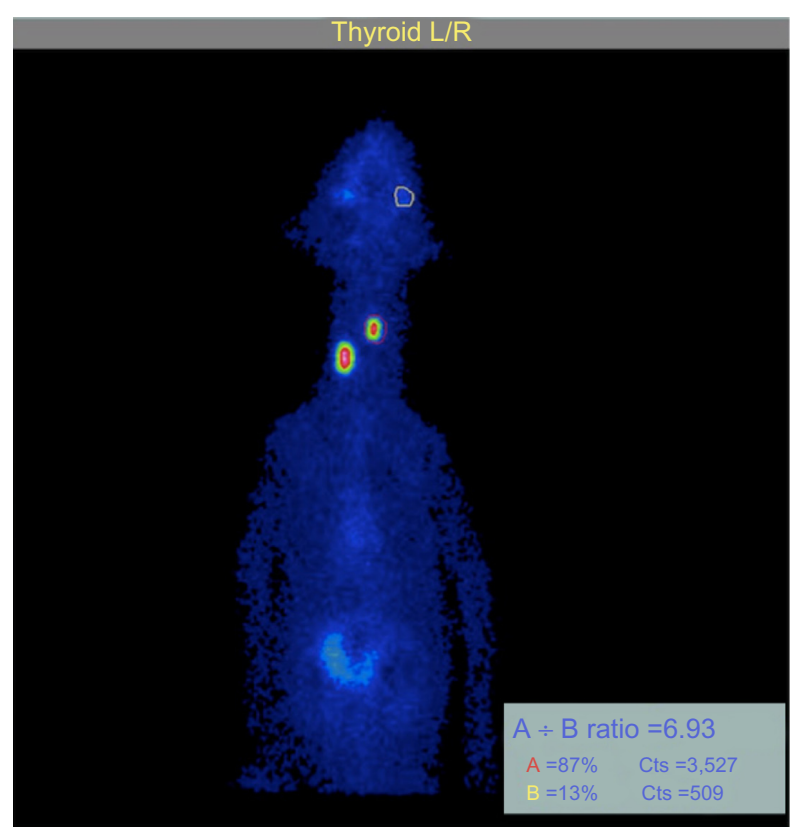

Figure I Cat with bilateral hyperthyroidism as seen by uptake of pertechnetate in both hyperplastic thyroid glands.

Notes: Note the region of interest around the left zygomatic molar salivary gland, as well as mild pertechnetate uptake in the gastric mucosa. The left thyroid to left zygomatic molar salivary gland ratio is 6.93 .

Abbreviations: A, thyroid gland; B, zygomatic salivary gland; Cts, counts; L, left; $\mathrm{R}$, right. palpation. Thyroid scintigraphy allows the extent of abnormal thyroid tissue to be determined. Scintigraphy in cats with true unilateral thyroid disease will reveal only one active thyroid gland because chronic TSH suppression leads to atrophy of the contralateral gland. In contrast, both thyroid glands are detected in cats with bilateral disease, despite the lack of circulating TSH. Bilateral hyperthyroidism typically results in asymmetric thyroid enlargement. The literature has reported that $3 \%-20 \%$ of hyperthyroid cats have abnormal functional thyroid tissue located in the cranial mediastinum, which can only be detected with scintigraphy. ${ }^{4,54}$ Although histopathology remains the gold standard for the diagnosis of thyroid carcinoma, thyroid scintigraphy can aid in the presumptive diagnosis via detection of masses that cannot be palpated. Although one report found no reliable features on scintigraphy to distinguish thyroid carcinoma from adenoma, ${ }^{55}$ others have described associations between malignancy and certain radionuclide uptake patterns. The patterns that have been associated with malignancy include uptake in the cranial mediastinum, detection of multiple and extensive regions of uptake, distorted, irregular uptake with activity extending beyond the thyroid gland margins, and detection of linear multifocal uptake patterns. ${ }^{3,56,57}$

\section{Thyroid ultrasound}

Ultrasonography can be utilized to evaluate the architecture of the thyroid glands; however, it is not useful for the diagnosis of hyperthyroidism. The normal feline thyroid gland is thin, fusiform-shaped, and approximately $15-25 \mathrm{~mm}$ in length, with uniform echogenicity and surrounded by a thin, hyperechoic capsule. ${ }^{4}$ Thyroid ultrasound examination of 15 hyperthyroid cats revealed thyroid glands that were larger with rounded margins, mixed echotexture, and increased vascularity compared with the appearance of the same glands 6 months after successful ${ }^{131} \mathrm{I}$ therapy. ${ }^{58}$ Sonographically determined volumes of single adenomatous glands from hyperthyroid cats were in the range of $552-572 \mathrm{~mm}^{3}$ compared with thyroid volumes in the range of $40-140 \mathrm{~mm}^{3}$ in cats with normal thyroid function. ${ }^{58,59}$

\section{Treatment options}

The major modalities currently available for the treatment of cats with hyperthyroidism include noncurative medical management with methimazole (Tapazole $^{\circledR}$; King Pharmaceuticals Inc.) and dietary management with Hill's $y / d^{\circledR}$ prescription diet (Hill's Pet Nutrition, Topeka, KS, USA) or curative therapy with surgery (thyroidectomy) and/or radioactive therapy $\left({ }^{131} \mathrm{I}\right)$. Each treatment modality 
has advantages and disadvantages, and treatment decisions should be based on the needs of each individual cat and its owner.

\section{Methimazole}

Medical management using oral methimazole is a commonly used noncurative treatment modality in the USA. Oral methimazole therapy provides an opportunity to adjust the dosage of antithyroid medication over time as needed; however, noncurative treatment necessitates daily lifelong administration of medication to control hyperthyroidism. Methimazole is a thioureylene compound that blocks the synthesis of thyroid hormones by inhibiting thyroid peroxidase activity, leading to reduced organification of iodide, as well as inhibition of the coupling of iodothyronines to form $\mathrm{T}_{3}$ and $\mathrm{T}_{4} \cdot{ }^{60}$ Methimazole does not inhibit the release of preformed, stored thyroid hormone, which delays the normalization of $\mathrm{T}_{4}$ concentrations by $2-4$ weeks after initiating therapy. ${ }^{39}$ Methimazole has a serum half-life of 2.3 hours in hyperthyroid cats and 4.7 hours in normal cats. ${ }^{60,61}$ Carbimazole, another antithyroid medication, is metabolized to methimazole after oral administration, making it as effective as methimazole. Carbimazole is widely used in Europe and Asia for the treatment of feline hyperthyroidism but is not licensed for this indication in the USA. ${ }^{29}$

Evaluation of 262 hyperthyroid cats treated with methimazole as the sole therapy revealed a decrease in $\mathrm{T}_{4}$ concentration after 2-3 weeks of therapy. ${ }^{39}$ Side effects associated with oral methimazole were reported in approximately $18 \%$ of treated cats, and included vomiting, anorexia, and depression, as well as self-induced excoriations of the face or neck, blood dyscrasias, and hepatopathy. ${ }^{39}$ These effects are typically observed within 2-4 weeks of initiation of methimazole therapy. If less severe side effects such as vomiting are observed, a decrease in methimazole dose can be attempted; however, if the more serious blood dyscrasias or hepatopathy occur, methimazole should be discontinued immediately, and supportive care should be instituted as necessary.

The recommended starting dose is $2.5 \mathrm{mg}$ methimazole orally twice daily., ${ }^{4,62}$ Although once-daily dosing has been advocated, twice-daily dosing has been found to be more effective. ${ }^{63}$ After 2-3 weeks on the starting dose, the serum total $\mathrm{T}_{4}$ should be determined; the target total $\mathrm{T}_{4}$ concentration is in the lower half of the reference interval. ${ }^{62,63} \mathrm{~A}$ recent study determined that the timing of blood collection after administration of methimazole is not crucial and does not affect the ability to assess the therapeutic response. ${ }^{64}$ Continued monitoring of total $\mathrm{T}_{4}$ concentrations should be done every 2-3 weeks after a dosage change, 3 months after initial stabilization of total $\mathrm{T}_{4}$, and every 6 months thereafter. ${ }^{62}$ If the serum total $\mathrm{T}_{4}$ concentration at recheck is within or just above the reference interval, the dose should be maintained. If the serum total $\mathrm{T}_{4}$ value is below the reference interval, a dose reduction of $2.5 \mathrm{mg}$ per day is indicated. ${ }^{62}$ If serum total $\mathrm{T}_{4}$ remains significantly elevated despite therapy, compliance should first be assessed, and if judged adequate, the methimazole dose should be increased by $2.5 \mathrm{mg}$ per day. ${ }^{4,62}$ Although the effects of methimazole on total $\mathrm{T}_{4}$ values are typically observed within the first week of initiation of therapy, resolution of clinical signs may not be observed for up to 6 weeks after euthyroidism is restored. ${ }^{4}$

Hyperthyroid cats with concurrent chronic kidney disease can present a treatment dilemma. Multiple studies have confirmed that treatment of hyperthyroidism with methimazole (as well as ${ }^{131}$ I and thyroidectomy) decreases the glomerular filtration rate. ${ }^{65-67}$ Although the decrease in glomerular filtration rate is a result of return to a euthyroid state rather than a consequence of the particular antithyroid therapy used, the decreased renal excretion can either unmask previously undiagnosed chronic kidney disease or exacerbate known chronic kidney disease. In non-azotemic cats with unrecognized early chronic kidney disease, it remains difficult to predict the magnitude of the decrease in glomerular filtration rate or the development of azotemia following successful treatment of hyperthyroidism. For this reason, it is historically recommended that treatment of cats with previously diagnosed renal disease start at a lower dose of methimazole, such as $1.25 \mathrm{mg}$ twice daily or $2.5 \mathrm{mg}$ once daily. In addition, a trial with oral methimazole is often recommended prior to pursuit of either thyroidectomy or ${ }^{131} \mathrm{I}$ to assess possible adverse renal function effects after restoration of euthyroidism.

During oral methimazole therapy, most cats exhibit only mild changes in renal function $(<30 \%$ increase in serum creatinine), which stabilizes within approximately 1 month after successful treatment of hyperthyroidism. ${ }^{32,67}$ In addition, although it is not uncommon for cats to experience azotemia after successful treatment of hyperthyroidism, it has been shown that those cats that develop azotemia post-methimazole or $\mathrm{I}^{131}$ therapy do not have a decreased overall survival time compared with cats that remain non-azotemic when treated for hyperthyroidism. ${ }^{68}$ There is increasing evidence that maintenance of a hyperthyroid state is detrimental to long-term renal function. For example, when evaluating the N-acetyl$\beta$-D-glucosaminidase index $\left(\mathrm{NAG}_{\mathrm{i}}\right)$, a specific marker of active proximal tubular damage, in 24 non-azotemic hyperthyroid cats treated with methimazole, the high $\mathrm{NAG}_{\mathrm{i}}$ levels in hyperthyroid cats decreased following therapy, indicating that the renal changes associated with hyperthyroidism can be reversed. ${ }^{69}$ Therefore, despite the risk of reduced renal 
function, maintaining total $\mathrm{T}_{4}$ values in the lower half of the reference interval is indicated for affected cats unless there is a profound increase in azotemia that adversely affects the cat's quality of life.

Although post-therapy azotemia, in the absence of pretherapy azotemia, has not been associated with decreased survival times, cats with hyperthyroidism and evidence of preexisting chronic kidney disease treated with oral methimazole or ${ }^{131} \mathrm{I}$ had significantly shorter survival times than hyperthyroid cats without evidence of renal disease. ${ }^{70}$ Overall, the median survival time of cats treated with methimazole alone has been reported as approximately 2 years, while those treated with methimazole followed by ${ }^{131} \mathrm{I}$ had a median survival time of 5.3 years. ${ }^{70}$ Another study of 300 hyperthyroid cats treated with oral methimazole or carbimazole alone or in combination with thyroidectomy found the overall median survival time to be 417 days. ${ }^{20}$ Of these 300 cats, the hyperthyroid cats with pretherapy azotemia had a significantly shorter median survival time (178 days) than non-azotemic cats (612 days). ${ }^{20}$

In addition to oral methimazole, compounded topical preparations of methimazole are available that are absorbed transdermally. Initial studies reported the bioavailability of transdermal methimazole to be poor after application of a single dose to the pinnae of healthy cats. ${ }^{71}$ However, longterm use of topical methimazole decreased total $\mathrm{T}_{4}$ concentrations and resulted in restored euthyroidism. ${ }^{72}$ Although the overall efficacy of transdermal methimazole was less than that of oral methimazole, and oral methimazole was significantly more effective than the transdermal formulation at 2 weeks post-therapy, the initial difference in $\mathrm{T}_{4}$ concentrations was no longer significant by 4 weeks post-therapy. ${ }^{73}$ These data suggest that chronic use of transdermal methimazole can be effective in lowering $\mathrm{T}_{4}$ concentrations. ${ }^{73}$ The recommended initial dose of the transdermal formulation is $5-10 \mathrm{mg}$ per cat, and once-daily application appears to be as effective in controlling total $\mathrm{T}_{4}$ as twice-daily application. ${ }^{74,75}$ Gastrointestinal side effects were found to occur less frequently with the transdermal formulation than with the oral formulation. ${ }^{73}$ Additional adverse effects associated with the transdermal formulation include mild crusting and erythema at the site of application. Overall, transdermal methimazole may be a viable option for some patients, but it must be remembered when using compounded medications that different compounded products can vary in efficacy and safety.

\section{Hill's $y / d^{\circledR}$ prescription diet}

Dietary iodine restriction is a newly developed therapy for feline hyperthyroidism. The only available commercial diet for the management of feline hyperthyroidism is Hill's $\mathrm{y} / \mathrm{d}$ prescription diet. The diet is markedly restricted in iodine content, which requires strict dietary compliance for successful management of hyperthyroidism, and concurrent use of this diet and methimazole is not recommended. ${ }^{76}$ Iodine is the major mineral component of thyroid hormones and its only known biologic function is the production of $\mathrm{T}_{3}$ and $\mathrm{T}_{4}$ hormones. ${ }^{36}$ Iodine content in commercial cat foods varies widely, ranging from undetectable to greater than $35 \mathrm{ppm}$. The absolute dietary iodine requirements for cats are unknown. Precise requirements are difficult to determine since the thyroid gland is able to adapt its function to wide variations in iodine intake, and other dietary ingredients such as perchlorate can interfere with thyroid usage of iodine and iodine measurements by analytical methods. ${ }^{36}$

The effects of dietary iodine restriction on the thyroid gland were evaluated by feeding nine cats with naturally occurring hyperthyroidism diets containing either $0.47 \mathrm{ppm}$, $0.28 \mathrm{ppm}$, or $0.17 \mathrm{ppm}$ iodine on a dry matter basis. ${ }^{77}$ When fed either the $0.47 \mathrm{ppm}$ iodine or $0.28 \mathrm{ppm}$ iodine diet, eight of the nine cats became euthyroid, while all nine cats became euthyroid when fed the $0.17 \mathrm{ppm}$ iodine diet. ${ }^{77}$ There were no adverse effects noted in any of the cats while feeding any of the iodine-restricted diets. ${ }^{77}$ The study concluded that iodine restriction is safe and effective for returning hyperthyroid cats to a euthyroid state. ${ }^{77}$ A subsequent study showed that hyperthyroid cats had significantly reduced serum total $\mathrm{T}_{4}$ concentrations at $0,3,6$, and 12 weeks when dietary iodine was reduced from $1.9 \mathrm{ppm}$ to $0.32 \mathrm{ppm} .{ }^{78}$ The results of feeding studies show that diets with $\leq 0.32 \mathrm{ppm}$ iodine lower serum total $\mathrm{T}_{4}$ in cats with naturally occurring hyperthyroidism. ${ }^{77-79}$

In a study of client-owned hyperthyroid cats, feeding iodine-restricted food ( $0.32 \mathrm{ppm}$ on a dry matter basis) decreased total $\mathrm{T}_{4}$ concentration and improved clinical signs after consuming the diet for 4 weeks. ${ }^{80}$ No adverse effects associated with feeding the iodine-restricted diet were observed. Although dietary iodine restriction appears to be a valid option in the management of hyperthyroidism in a subset of hyperthyroid cats in which strict dietary compliance can be achieved, there is concern that many cats do not achieve total $\mathrm{T}_{4}$ values in the lower half of the reference interval, indicating optimal control of hyperthyroidism may be difficult via modification of diet alone.

\section{Thyroidectomy}

Thyroidectomy is curative for feline hyperthyroidism, but the popularity of surgical treatment has declined over the past decade, in part due to the risk of significant postoperative complications and because of the development and availability 
of nonsurgical treatment options. Since over $70 \%$ of hyperthyroid cats have bilateral thyroid disease, ${ }^{2}$ curative surgery requires bilateral thyroidectomy for most cats. ${ }^{81}$ Multiple surgical procedures have been described, ${ }^{81-84}$ but complete discussion of surgical approaches is beyond the scope of this review. Morbidity associated with surgical approaches results from disruption of important structures in proximity to the thyroid glands, including the parathyroid glands, the carotid arteries, jugular veins, and recurrent laryngeal nerves. The most serious postoperative complication is severe hypocalcemia caused by iatrogenic damage or removal of the parathyroid gland(s) during surgery. ${ }^{81-83}$ Horner's syndrome and laryngeal dysfunction (voice change) or laryngeal paralysis are other possible surgical complications. ${ }^{81-83}$ Along with surgical complications specific to the thyroidectomy, geriatric hyperthyroid cats are often in poor body condition and may have other concurrent disease(s), making them less desirable anesthetic candidates. In addition to surgical complications, treatment failures can also occur either due to persistent hyperthyroidism or permanent hypothyroidism. Persistent hyperthyroidism can result from incomplete thyroidectomy, or presence of ectopic thyroid tissue, while permanent hypothyroidism can result from removal of all functional thyroid tissue via bilateral thyroidectomy. ${ }^{81-83}$

Of 101 cats that underwent either unilateral or bilateral thyroidectomy, two died within 72 hours of surgery. Follow-up 59 months after thyroidectomy revealed 57 cats were still alive with a median survival time of 1.9 years, and 44 cats that were no longer alive had had a median survival time of 1.1 years. ${ }^{85}$ Reported causes of death included renal failure, other malignant tumors, megacolon, aortic thrombosis, respiratory problems, seizures, urinary tract problems, viral infections, and liver disease. Ultimately, if thyroidectomy is chosen as the primary treatment for hyperthyroidism, euthyroidism should be achieved prior to surgery via medical or dietary management. Euthyroidism at the time of surgery may diminish the risk of cardiac complications associated with anesthesia and permits assessment of renal function prior to thyroidectomy.

\section{Radioiodine therapy}

Radioactive iodine $\left({ }^{131} \mathrm{I}\right)$ is a curative treatment for feline hyperthyroidism and is the treatment of choice for most cats due to its high cure rate and minimal side effects. Because iodine transporters on thyroid cells do not differentiate radioactive iodine from naturally occurring iodine, the radioactive isotope is able to concentrate within the thyroid gland. ${ }^{131}$ I emits $\beta$-particles and $\gamma$-rays, which destroy any surround- ing functional thyroid tissue. ${ }^{4} \beta$-particles are responsible for the majority of the clinical effect by causing pyknosis and necrosis of thyroid follicular cells as well as vascular and stromal fibrosis of the gland. ${ }^{4}$ The emitted radiation travels on average only $400 \mu \mathrm{m}$ within thyroid tissue and spares surrounding tissues such as the parathyroid glands. ${ }^{4}$ In addition, atrophied thyroid tissue is unaffected by ${ }^{131}$ I due to its inability to uptake iodine, making ${ }^{131}$ I the only treatment modality to specifically target hyperfunctioning thyroid tissue. ${ }^{86}$

${ }^{131} \mathrm{I}$ is typically administered by subcutaneous injection, although intravenous and oral administration is also acceptable. ${ }^{40}$ Several methods for calculating an ${ }^{131}$ I dose have been described..$^{3,4,87,88}$ Ultimately, treatment protocols that use variable ${ }^{131} \mathrm{I}$ doses (tailored to individual cats) have no advantage over protocols that employ a fixed ${ }^{131} \mathrm{I}$ dose, so most treatment centers report use of a fixed-dose protocol that administers 3-6 mCi per cat. ${ }^{40,54,86,87}$ A study that evaluated 524 hyperthyroid cats treated with radioiodine used a single dose of $2-6 \mathrm{mCi}{ }^{131} \mathrm{I} .{ }^{40}$ The administered dose was determined using a combination of severity of clinical signs, magnitude of serum $\mathrm{T}_{4}$ elevation, and size of the thyroid gland(s) measured by digital palpation. ${ }^{40}$ The investigators reported that there was complete resolution of clinical signs of hyperthyroidism and return of serum total $\mathrm{T}_{4}$ concentration to within the reference interval in $94.2 \%$ of cases within 6-12 months of radioiodine therapy; only eight cats remained hyperthyroid and eleven developed clinical hypothyroidism 12 months after ${ }^{131}$ I treatment. Based on these results, it is recommended that cats that remain hyperthyroid after an initial ${ }^{131}$ I treatment should not undergo a second treatment until persistent hyperthyroidism has been documented at 6 months post-therapy. ${ }^{40}$

${ }^{131} \mathrm{I}$ doses of $10-30 \mathrm{mCi}$ carry the best chance of completely destroying malignant thyroid tissue, making it the treatment of choice in cats with confirmed thyroid carcinoma, regardless of tumor location, including pulmonary metastases. ${ }^{3,89}$ Larger doses of ${ }^{131} \mathrm{I}$ are needed for carcinomas because malignant thyroid cells do not concentrate or retain ${ }^{131} \mathrm{I}$ as effectively as adenomatous cells. ${ }^{3,55,89}$ The use of high-dose radioiodine in cats after thyroidectomy for carcinoma has been associated with a high rate of posttreatment hypothyroidism requiring thyroxine supplementation. ${ }^{89}$ However, another study that evaluated a single high dose of ${ }^{131} \mathrm{I}$ as the sole therapy, found that six of seven cats with confirmed thyroid carcinoma had complete clinical resolution of hyperthyroidism and none of the cats had clinically significant hypothyroidism requiring supplementation post- ${ }^{131}$ I treatment. ${ }^{55}$ 
Potential disadvantages of ${ }^{131} \mathrm{I}$ therapy include persistent hyperthyroidism requiring a second ${ }^{131} \mathrm{I}$ treatment or use of antithyroid medication, as well as post- ${ }^{131} \mathrm{I}$ treatment hypothyroidism. ${ }^{40,86}$ Of 524 cats treated with a mean radioiodine dose of $3.4 \mathrm{mCi}$, the percentage of cats with relapse of hyperthyroidism was only $2.5 \%$ and the prevalence of clinical hypothyroidism requiring thyroid supplementation was only $2.1 \%{ }^{40}$ Additional disadvantages of radioiodine therapy include the need for patients to be housed separately for 7-10 days after treatment or until radioactivity falls to safe levels as determined by state regulations. After discharge from the hospital, many cats will continue to emit low doses of radiation for approximately 2 weeks, which necessitates additional precautions be implemented to avoid unnecessary exposure of pet owners. In addition to specific in-hospital housing requirements, staff with radiation safety training are needed to care for the cats in the post-treatment period. Due to these factors, there is a relatively high upfront (but one time) cost for ${ }^{131}$ I therapy.

In general, ${ }^{131} \mathrm{I}$ is a highly efficacious treatment modality, with $95 \%$ of cats becoming euthyroid within 3 months of receiving a single treatment. ${ }^{4}$ The median survival times associated with ${ }^{131} \mathrm{I}$ therapy have been found to be comparable with or longer than those reported for cats that undergo surgical thyroidectomy. ${ }^{85}$ The median survival time of the abovementioned 524 cats that received ${ }^{131} \mathrm{I}$ was approximately 2 years. ${ }^{40}$ Other reported median survival times for cats that received ${ }^{131} \mathrm{I}$ for treatment of hyperthyroidism are 25 months ${ }^{90}$ and 4 years. ${ }^{70}$ Overall, due to the high efficacy rate for controlling feline hyperthyroidism, as well as the low incidence of adverse effects, ${ }^{131}$ I remains the curative treatment of choice for feline hyperthyroidism.

\section{Treatment-associated hypothyroidism}

Upon instituting therapy for hyperthyroidism, in addition to monitoring total $\mathrm{T}_{4}$ concentrations to ensure euthyroidism, one must also consider the potential for iatrogenic hypothyroidism. Not all cats with decreased total $\mathrm{T}_{4}$ values exhibit clinical signs of hypothyroidism. Hypothyroidism has been associated with decreased glomerular filtration rate, and thus could have significant consequences in cats with preexisting renal disease. Cats that developed iatrogenic hypothyroidism had a greater incidence of azotemia than cats that were euthyroid following treatment for hyperthyroidism. ${ }^{32}$ In addition, cats with iatrogenic hypothyroidism were more likely to develop azotemia within 6 months after treatment of hyperthyroidism, and hypothyroid cats with azotemia have decreased survival times compared with hypothyroid non-azotemic cats. ${ }^{32,91}$ Finally, it has been demonstrated that restoration of euthyroidism via dose adjustments of antithyroid medication in cats with iatrogenic hypothyroidism improves renal function. ${ }^{92}$

\section{Conclusion}

Hyperthyroidism is the most commonly diagnosed endocrinopathy in older cats, and its recognition and diagnosis are important for small animal practitioners. The pros and cons of the available treatment options as well as long-term monitoring requirements should be discussed in detail with cat owners to ensure the most appropriate treatment plan is initiated for each individual cat. The costs associated with each treatment option vary based on the facility, and the relatively larger upfront cost of thyroidectomy and ${ }^{131} \mathrm{I}$ must be compared with the monthly costs associated with the noncurative treatment options. Due to the lack of a randomized trial evaluating all the different treatment options, it is difficult to state the superiority of one treatment modality over the other, emphasizing the need to tailor therapy to each individual cat and owner needs.

\section{Disclosure}

The authors (HH Vaske, and GF Grauer) currently have research funding from Hill's Pet Nutrition. The authors have no further conflicts of interest in this work.

\section{References}

1. Peterson ME, Johnson JG, Andrews LK. Spontaneous hyperthyroidism in the cat. Am Cell Vet Intern Med. 1979;108:Abstract.

2. Peterson ME, Kintzer PP, Cavanagh PG, et al. Feline hyperthyroidism: pretreatment clinical and laboratory evaluation of 131 cases. J Am Vet Med Assoc. 1983;183(1):103-110.

3. Turrel JM, Feldman EC, Nelson RW, Cain GR. Thyroid carcinoma causing hyperthyroidism in cats: 14 cases. J Am Vet Med Assoc. 1988; 193(3):359-364.

4. Feldman EC, Nelson RW. Feline hyperthyroidism (thyrotoxicosis). In: Feldman EC, Nelson RW, editors. Canine and Feline Endocrinology and Reproduction. 3rd ed. St Louis, MO, USA: Elsevier Saunders; 2004.

5. Kennedy RL, Thoday KL. Autoantibodies in feline hyperthyroidism. Res Vet Sci. 1988;45(3):300-306.

6. Peterson ME, Livingston P, Brown RS. Lack of circulating thyroid stimulating immunoglobulins in cats with hyperthyroidism. Vet Immunol Immunopathol. 1987;16(3-4):277-282.

7. Nguyen LQ, Arseven OK, Gerber H, Stein BS, Jameson JL, Kopp P. Cloning of the cat TSH receptor and evidence against an autoimmune etiology of feline hyperthyroidism. Endocrinology. 2002;143(2):395-402.

8. Kass PH, Peterson ME, Levy J. Evaluation of environmental, nutritional, and host factors in cats with hyperthyroidism. J Vet Intern Med. 1999;13(4):323-329.

9. Martin KM, Rossing MA, Ryland LM, DiGiacomo RF, Freitag WA Evaluation of dietary and environmental risk factors for hyperthyroidism in cats. $J$ Am Vet Med Assoc. 2000;217(6):853-856.

10. Edinboro CH, Scott-Moncrieff JC, Janovitz E, Thacker HL, Glickman LT. Epidemiologic study of relationships between consumption of commercial canned food and risk of hyperthyroidism in cats. $J$ Am Vet Med Assoc. 2004;224(6):879-886. 
11. Olczak J, Jones BR, Pfeiffer DU, Squires RA, Morris RS, Markwell PJ. Multivariate analysis of risk factors for feline hyperthyroidism in New Zealand. N Z Vet J. 2004;53(1):53-58.

12. Scarlett JM, Moise NS, Rayl J. Feline hyperthyroidism: a descriptive and case-control study. Prev Vet Med. 1988;6(4):295-309.

13. Peterson ME, Ward CR. Etiopathologic findings of hyperthyroidism cats. Vet Clin North Am Small Anim Pract. 2007;37(4):633-645.

14. Broussard JD, Peterson ME, Fox PR. Changes in clinical and laboratory findings in cats with hyperthyroidism from 1983-1993. J Am Vet Med Assoc. 1995;206(3):302-305.

15. Thoday KL, Mooney CT. Historical, clinical and laboratory features of 126 hyperthyroid cats. Vet Rec. 1992;131(12):257-264.

16. Baral R, Peterson ME. Thyroid gland disorders. In: Little SE, editor. The Cat: Clinical Medicine and Management. Philadelphia, PA, USA: Elsevier Saunders; 2012.

17. Klein I, Ojamaa K. Thyroid hormone and the cardiovascular system. N Engl J Med. 2001;344(7):501-509.

18. Syme HM. Cardiovascular and renal manifestations of hyperthyroidism. Vet Clin North Am Small Anim Pract. 2007;37(4):723-743.

19. Marrow LD, Adams VJ, Elliott J, et al. Hypertension in hyperthyroid cats: prevalence, incidence, and predictors of its development. $J$ Vet Intern Med. 2009;23(3):699.

20. Williams TL, Peak KJ, Brodbelt D, et al. Survival and the development of azotemia after treatment of hyperthyroid cats. $J$ Vet Intern Med. 2010;24(4):863-869.

21. Kobayashi DL, Peterson ME, Graves TK, Elliot J, Syme HM. Hypertension in cats with chronic renal failure or hyperthyroidism. $J$ Vet Intern Med. 1990;4(2):58-62.

22. Mooney CT. Hyperthyroidism. In: Ettinger SJ, Feldman EC, editors. Textbook of Veterinary Internal Medicine. 7 th ed. St Louis, MO, USA: Elsevier Saunders; 2010.

23. Upadhyay G, Singh R, Kumar A. Severe hyperthyroidism induces mitochondria-mediated apoptosis in rat liver. Hepatology. 2004;39(4): $1120-1130$.

24. Andican G, Gelisgen R, Civelek S, et al. Oxidative damage to nuclear DNA in hyperthyroid rat liver: inability of vitamin $\mathrm{C}$ to prevent the damage. J Toxicol Environ Health. 2004;67(5):413-420.

25. Horney BS, Farmer AJ, Honor DJ, MacKenzie A, Burton S. Agarose gel electrophoresis of alkaline phosphatase isoenzymes in the serum of hyperthyroid cats. Vet Clin Pathol. 1994;23(3):98-102.

26. Archer FJ, Taylor SM. Alkaline phosphatase bone isoenzymes and osteocalcin in the serum of hyperthyroid cats. Can Vet J. 1996;37(12): 735-739.

27. Foster DJ, Thoday KL. Tissue sources of serum alkaline phosphatase in 34 hyperthyroid cats: a qualitative and quantitative study. Res Vet Sci. 2000;68(1):89-94.

28. Berent AC, Drobatz KJ, Ziemer L. Liver function in cats with hyperthyroidism before and after 131I therapy. JVet Intern Med. 2007;21(6): $1217-1223$

29. Mooney CT, Thoday KL, Doxey DL. Carbimazole therapy of feline hyperthyroidism. J Small Anim Pract. 1992;33(5):228-235.

30. Adams WH, Daniel GB, Legendre AM, Gompf RE, Grove CA. Changes in renal function in cats following treatment of hyperthyroidism using 131I. Vet Radiol Ultrasound. 1997;38(3):231-238.

31. Guyton AC, Hall JE. Thyroid metabolic hormones. In: Guyton AC, Hall JE, editors. Textbook of Medical Physiology. 11th ed. Philadelphia, PA, USA: Elsevier Inc.; 2006.

32. van Hoek I, Lefebvre HP, Peremans K, et al. Short- and long-term follow-up of glomerular and tubular renal markers of kidney function in hyperthyroid cats after treatment with radioiodine. Domest Anim Endocrinol. 2009;36(1):45-56.

33. Mayer-Poenne B, Goldstein RE, Erb HN. Urinary tract infections in cats with hyperthyroidism, diabetes mellitus and chronic kidney disease. J Feline Med Surg. 2007;9(2):124-132.

34. Bailiff NL, Westropp JL, Nelson RW. Evaluation of urine specific gravity and urine sediment as risk factors for urinary tract infections in cats. Vet Clin Pathol. 2008;37(3):317-322.
35. Kaptein EM, Hays MT, Ferguson DC. Thyroid hormone metabolism. A comparative evaluation. Vet Clin North Am Small Anim Pract. 1994;24(3):431-466.

36. Zicker S, Schoenherr B. Focus on nutrition: the role of iodine in nutrition and metabolism. Compend Contin Educ Vet. 2012;34(10):E1-E4.

37. Peterson ME, Melian C, Nichols R. Measurement of serum concentrations of free thyroxine, total thyroxine, and total triiodothyronine in cats with hyperthyroidism and cats with nonthyroidal disease. J Am Vet Med Assoc. 2001;218(4):529-536.

38. Peterson ME. Diagnostic testing for hyperthyroidism in cats: more than just $\mathrm{T}_{4}$. J Feline Med Surg. 2013;15(9):765-777.

39. Peterson ME, Kintzer PP. Methimazole treatment of 262 cats with hyperthyroidism. J Vet Intern Med. 1988;2(3):150-157.

40. Peterson ME, Becker DV. Radioiodine treatment of 524 cats with hyperthyroidism. J Am Vet Med Assoc. 1995;207(11):1422-1428.

41. Horney BS, MacKenzie AL, Burton SA, et al. Evaluation of an automated, homogenous enzyme immunoassay for serum thyroxine measurement in dog and cat serum. Vet Clin Pathol. 1999;28(1): $20-28$.

42. Lurye JC, Behrend EN, Kemppainen RJ. Evaluation of an in-house enzyme-linked immunosorbent assay for the quantitative measurement of serum total thyroxine concentration in dogs and cats. J Am Vet Med Assoc. 2002;221(2):243-249.

43. Kemppainen RJ, Birchfield JR. Measurement of total thyroxine concentration in serum from dogs and cats by use of various methods. Am J Vet Res. 2006;67(2):259-265.

44. Peterson ME. Feline focus: diagnostic testing or feline thyroid disease: hyperthyroidism. Compend Contin Educ Vet. 2013;35(8):E3.

45. Mooney CT, Little CJ, Macrae AW. Effects of illness not associated with the thyroid gland on serum total and free thyroxine concentrations in cats. J Am Vet Med Assoc. 1996;208(12):2004-2008.

46. Wakeling J, Moore K, Elliot J, Syme SH. Diagnosis of hyperthyroidism in cats with mild chronic kidney disease. J Small Anim Pract. 2008;49(6):287-294.

47. Peterson ME, Graves TK, Gamble DA. Triiodothyronine (T3) suppression test. An aid in the diagnosis of mild hyperthyroidism in cats. J Vet Intern Med. 1990;4(5):233-238.

48. Peterson ME, Broussard JD, Gamble DA. Use of the thyrotropin releasing hormone stimulation test to diagnose mild hyperthyroidism in cats. J Vet Intern Med. 1994;8(4):279-286.

49. Tomsa K, Glaus TM, Kacl GM. Thyrotropin-releasing hormone stimulation test to assess thyroid function in severely sick cats. $J$ Vet Intern Med. 2001;15(2):89-93.

50. Wakeling J, Elliott J, Syme H. Evaluation of predictors for the diagnosis of hyperthyroidism in cats. J Vet Intern Med. 2011;25(5):1057-1065.

51. Beck KA, Hornof WJ, Feldman EC. The normal feline thyroid: technetium pertechnetate imaging and determination of thyroid to salivary gland radioactivity ratios in 10 normal cats. Vet Radiol Ultrasound. 1985;26(1):35-38.

52. Daniel GB, Sharp DS, Mieckarz JA, Adams W. Quantitative thyroid scintigraphy as a predictor of serum thyroxin concentration in normal and hyperthyroid cats. Vet Radiol Ultrasound. 2001;43(4):374-382.

53. Nieckarz JA, Daniel GB. The effect of methimazole on thyroid uptake of pertechnetate and radioiodine in normal cats. Vet Radiol Ultrasound. 2001;42(5):448-457.

54. Harvey AM, Hibbert A, Barrett EL, et al. Scintigraphy findings in 120 hyperthyroid cats. J Feline Med Surg. 2009;11(2):96-106.

55. Hibbert A, Gruffydd-Jones T, Barret EL. Feline thyroid carcinoma: diagnosis and response to high-dose radioactive iodine treatment. J Feline Med Surg. 2009;11(2):116-124.

56. Peterson M, Becker D. Radionuclide thyroid imaging in 135 cats with hyperthyroidism. Vet Radiol Ultrasound. 1984;25(1):23-27.

57. Broome MR. Thyroid scintigraphy in hyperthyroidism. Clin Tech Small Anim Pract. 2006;21(1):10-16.

58. Barberet V, Baeumlin Y, Taeymans O, et al. Pre- and posttreatment ultrasonography of the thyroid gland in hyperthyroid cats. Vet Radiol Ultrasound. 2010;51(3):324-330. 
59. Wisner ER, Theon AP, Nyland TG, et al. Ultrasonographic examination of the thyroid gland of hyperthyroid cats: comparison to 99mTc scintigraphy. Vet Radiol Ultrasound. 1994;35(1):53.

60. Trepanier LA, Peterson ME, Aucoin DP. Pharmacokinetics of methimazole in normal cats and cats with hyperthyroidsm. Res Vet Sci. 1991;50(1):69-74.

61. Papich MG. Methimazole. In: Saunders Handbook of Veterinary Drugs. 3rd ed. St Louis, MO, USA: Elsevier Saunders; 2011.

62. Daminet S, Kooistra HS, Fracassi F, et al. Best practice for the pharmacological management of hyperthyroid cats with antithyroid drugs. J Small Anim Pract. 2014;55(1):4-13.

63. Trepanier LA, Hoffman SB, Kroll M, Rodan I, Challoner L. Efficacy and safety of once versus twice daily administration of methimazole in cats with hyperthyroidism. J Am Vet Med Assoc. 2003;222(7): 954-958.

64. Rutland BE, Nachreiner RF, Kruger JM. Optimal testing for thyroid hormone concentration after treatment with methimazole in healthy and hyperthyroid cats. J Vet Intern Med. 2009;23(5): 1025-1030.

65. Graves TK, Olivier NB, Nachreiner RF, Kruger JM, Walshaw R, Stickle RL. Changes in renal function associated with treatment of hyperthyroidism in cats. Am J Vet Res. 1994;55(12):1745-1749.

66. Becker TJ, Graves TK, Kruger JM, Braselton WE, Nachreiner RF. Effects of methimazole on renal function in cats with hyperthyroidism. J Am Anim Hosp Assoc. 2000;36(3):215-223.

67. Boag AK, Neiger R, Slater L, Stevens KB, Haller M, Church DB. Changes in the glomerular filtration rate of 27 cats with hyperthyroidism after treatment with radioactive iodine. Vet Rec. 2007;161(21): 711-715.

68. Riensche MR, Graves TK, Schaeffer DJ. An investigation of predictors of renal insufficiency following treatment of hyperthyroidism in cats. $J$ Feline Med Surg. 2008;10(2):160-166.

69. Lapointe C, Bélanger MC, Dunn M, Moreau M, Bédard C. N-acetyl$\beta$-D-glucosaminidase index as an early biomarker for chronic kidney disease in cats with hyperthyroidism. J Vet Intern Med. 2008;22(5):1103-1110.

70. Milner RJ, Channell CD, Levy JK. Survival times for cats with hyperthyroidism treated with iodine 131, methimazole or both: 167 cases (1996-2003). J Am Vet Med Assoc. 2006;228(4):559-563.

71. Hoffman S, Yoder A, Trepanier L. Bioavailability of transdermal methimazole in a pluronic lecithin organogel (PLO) in healthy cats. $J$ Vet Pharmacol Ther. 2002;25(3):189-193.

72. Hoffmann G, Marks S, Taboada J, Rodan I, Challoner L. Transdermal methimazole treatment in cats with hyperthyroidism. J Feline Med Surg. 2003;5(2):77-82.

73. Sartor LL, Trepanier LA, Kroll MM, et al. Efficacy and safety of transdermal methimazole in the treatment of cats with hyperthyroidism. $J$ Vet Intern Med. 2004;18(5):651-655.

74. Hill KE, Gieseg MA, Kingsbury D, Lopez-Villabolos N, Bridges J, Chambers P. The efficacy and safety of a novel lipophilic formulation of methimazole for the once daily transdermal treatment of cats with hyperthyroidism. J Vet Intern Med. 2011;25(6):1357-1365.
75. Boretti FS, Sieber-Ruckstuhl NS, Schafer S, et al. Duration of T4 suppression in hyperthyroid cats treated once and twice daily with transdermal methimazole. J Vet Intern Med. 2013;27(2):377-381.

76. Hill's Pet Nutrition Inc, Guidelines for management of feline hyperthyroidism, copyright 2012 [webpage on the Internet]. Topeka: Hill's Pet Nutrition Inc.; 2014. Available from: www.hillsvet.com/thyroid.htm. Accessed October 20, 2012.

77. Melendez LD, Yamka RM, Forrester SD, et al. Titration of dietary iodine for reducing serum thyroxine concentrations in newly diagnosed hyperthyroid cats. J Vet Intern Med. 2011;25(4):683 (Abstract).

78. Yu S, Wedekind PA, Burris DS, et al. Controlled level of dietary iodine normalizes serum total thyroxine in cats with naturally occurring hyperthyroidism. J Vet Intern Med. 2011;25(4):683-684.

79. Melendez LD, Yamka RM, Burris PA. Titration of dietary iodine for maintaining normal serum thyroxine concentrations in hyperthyroid cats. J Vet Intern Med. 2011;25(4):683 (Abstract).

80. van der Kooij M, Bacvarova I, Meyer HP, et al. Effects of an iodine-restricted food on client-owned cats with hyperthyroidism. J Feline Med Surg. 2014;16(4):1-8.

81. Flanders JA. Surgical options for the treatment of hyperthyroidism in the cat. J Feline Med Surg. 1999;1(3):127-134.

82. Welches CD, Scavelli TD, Matthiesen DT, et al. Occurrence of problems after three techniques of bilateral thyroidectomy in cats. Vet Surg. 1989;18(5):392-396.

83. Padgett S. Feline thyroid surgery. Vet Clin North Am Small Anim Pract 2002;32(4):851-859.

84. Birchard SJ. Thyroidectomy in the cat. Clin Tech Small Anim Pract. 2006;21(1):29-33.

85. Naan EC, Kirpensteijn J, Kooistra H. Results of thyroidectomy in 101 cats with hyperthyroidism. Vet Surg. 2006;35(3):287-293.

86. Chun R, Garrett LD, Sargeant J, Sherman A, Hoskinson JJ. Predictors of response to radioiodine therapy in hyperthyroid cats. Vet Radiol Ultrasound. 2002;43(6):587-591.

87. Meric SM, Rubin SI. Serum thyroxine concentrations following fixed-dose radioactive iodine treatment in hyperthyroid cats: 62 cases (1986-1989). J Am Vet Med Assoc. 1990;197(5):621-623.

88. Broome MR, Turrel JM, Hays M. Predictive value of tracer studies for 131I treatment in hyperthyroid cats. Am J Vet Res. 1988;49(2):193-197.

89. Guptill L, Scott-Moncrieff CR, Janvits EB, Blevins WE, Yohn SE, DeNicola DB. Response to high-dose radioactive iodine administration in cats with thyroid carcinoma that had previously under gone surgery. J Am Vet Med Assoc. 1995;207(8):1055-1058.

90. Slater MR, Geller S, Roger K. Long-term health and predictors of survival for hyperthyroid cats treated with iodine 131. JVet Intern Med. 2001;15(1):47-51.

91. Wakeling J, Rob C, Elliott J. Survival of hyperthyroid cats is not affected by post-treatment azotemia. J Vet Intern Med. 2006;20(6):1523.

92. Williams TL, Elliot J, Syme HM. Restoration of euthyroidism in medically treated hyperthyroid cats with iatrogenic hypothyroidism (IM) improves renal function. J Vet Intern Med. 2012;26(3):753-754. 


\section{Publish your work in this journal}

Veterinary Medicine: Research and Reports is an international, Visit http://www.dovepress.com/testimonials.php to read real quotes peer-reviewed, open access journal publishing original research, from published authors.

case reports, editorials, reviews and commentaries on all areas of veterinary medicine. The manuscript management system is completely online and includes a very quick and fair peer-review system.

Submit your manuscript here: http://www.dovepress.com/veterinary-medicine-research-and-reports-journal 